\title{
STUDY OF SINONASAL VARIATIONS BY CT SCAN AND NASAL ENDOSCOPY IN CHRONIC SINUSITIS: A PROSPECTIVE CLINICAL STUDY
}

\author{
A. V. S. Hanumantha Rao', B. Vijay Kumar², J. Suresh Babu³ \\ ${ }^{1}$ Associate Professor, Department of ENT, Kakatiya Medical College, Warangal. \\ ${ }^{2}$ Assistant Professor, Department of ENT, Kakatiya Medical College, Warangal. \\ ${ }^{3}$ ENT Surgeon, Department of ENT, Tenali, Andhra Pradesh.
}

\section{ABSTRACT}

\section{BACKGROUND}

Fifty patients with chronic sinusitis evaluated thoroughly and CT findings of those patients were correlated with nasal endoscopy findings. Chronic sinusitis is one of the commonest nasal diseases. It is more often seen in patients with sinonasal variations. A prospective clinical study was conducted in fifty patients of chronic sinusitis. All of them were subjected for CT scan and Nasal Endoscopy. It was observed that sinonasal variations are seen in majority cases of chronic sinusitis. Hence, it is concluded to subject every patient of chronic sinusitis to CT scan of nose and PNS, diagnostic nasal endoscopy before planning for surgical treatment.

\section{KEYWORDS}

Chronic Sinusitis, CT Scan of Nose and PNS and Nasal Endoscopy.

HOW TO CITE THIS ARTICLE: Rao AVSH, Kumar BV, Babu JS. Study of sinonasal variations by CT scan and nasal endoscopy in chronic sinusitis: a prospective clinical study. J. Evolution Med. Dent. Sci. 2016;5(24):1300-1305, D0I: 10.14260/jemds/2016/304

\section{INTRODUCTION}

The two cardinal factors in the maintenance of normal physiology of the paranasal sinuses and their mucous membranes are drainage and ventilation. Mucous transport from the sinuses into the nose is greatly enhanced by unimpeded nasal airflow creating negative pressure within the nasal cavity during inspiration. The secretions of the various sinuses do not reach their respective ostia randomly, but by definite pathways which seem genetically determined. The two of the largest sinuses, the frontal and maxillary, communicate with the middle meatus via narrow and delicate prechambers. In each of these prechambers, the mucosal surfaces are closely opposed such that mucus can be more readily cleared by an effective ciliary action on two or more sides.

However, when surfaces become more closely apposed due to mucosal swelling, the ciliary action is immobilized. This impairs the ventilation and drainage of larger sinuses, result in mucus stasis, predispose to further infection and establish a vicious cycle causing chronic sinusitis. ${ }^{1}$ The key region for these changes is that part of the lateral nasal wall that encloses the sinus ostia and their adjacent mucosa and prechambers. There is considerable anatomical variation in this area that may interfere with normal nasal function and predispose to recurrent or chronic sinusitis. ${ }^{2}$ Functional endoscopic sinus surgery restores normalcy by working on the key regions rather than on the larger sinuses. The safe and effective performance of any surgery is dependent on a sound knowledge of anatomy. This is most true during endoscopic sinus surgery because of the intimate association with such vital structures as the orbit, optic nerve, anterior and posterior ethmoidal vessels, skull base and internal carotid artery.

Financial or Other, Competing Interest: None.

Submission 09-02-2016, Peer Review 04-03-2016,

Acceptance 11-03-2016, Published 24-03-2016.

Corresponding Author:

A. V.S. Hanumantha Rao,

Flat No. 204, Gharonda Aangan,

Ram Nagar, Hyderabad-500044,

Telangana.

E-mail: suresh111161@gmail.com

DOI: $10.14260 /$ jemds/2016/304
The difficulty is compounded by the occurrence of variations in sinonasal anatomy. The incidence with which these variations are seen in a normal population is less frequent than in those individuals with chronic sinusitis. The incidence of the sinonasal anatomical variation reported in literature shows considerable variation between populations. This study aims to study the various sinonasal anatomical variations in our population.

\section{MATERIAL AND METHODS}

This present study is a prospective study of sinus diseases using diagnostic endoscopy and computed tomography was conducted in the Department of ENT, Mahathma Gandhi Memorial Hospital, Warangal.

\section{Source of Data}

All the patients attending the ENT Outpatient Department, who had chronic sinusitis for more than three months' duration not responding to the medical line of treatment and who were willing to undergo Functional Endoscopic Sinus Surgery.

\section{Sample Size: $\mathbf{5 0}$ \\ Sampling: Prospective Study}

\section{Inclusion Criteria}

All the patients with clinically proven chronic sinusitis not responding to routine medical line of treatment.

\section{Exclusion Criteria}

1. Patients with acute attack of sinusitis.

2. Patient with sinus malignancies.

3. Patient who were not willing to undergo FESS.

\section{Methods of Collection of Data}

1. The cases selected for the study were subjected to detailed history taking and examination.

2. A routine haemogram (HB, BT, CT, TC, DC) and urine examination (Albumin, Sugar, Microscopy), swab from middle meatus for culture sensitivity along with X-ray paranasal sinuses were done for the patients. 
3. All the patients in active stage of the disease were treated with course of suitable antibiotic, systemic antihistamines and local decongestants. They were also treated for medical conditions like diabetes mellitus, hypertension, nasal allergy. No patient received steroid therapy or immunotherapy.

4. Each patient underwent a systematic diagnostic nasal endoscopy and computed tomography of nose and paranasal sinuses.

\section{Equipment Used \\ Nasal Endoscope}

Karl Storz Hopkins rod optical with cold light source and fibre optic light delivery system. Endoscopes used were with 0, 30, 45 and 70 degree angles of view of $4 \mathrm{~mm}$ diameters.

Karl Storz Endovision Telecam deluxe camera system with monitor. Topical decongestant and anaesthetic agent (4\% Xylocaine with 1:100.000 adrenaline).

Antifog solutions (Savlon).

Suction apparatus, Cannula, Ball probe and Freer's elevator.

\section{Position}

Supine with head slightly elevated and turned towards the examiner, who is standing at the right side of the patient.

\section{Anaesthesia}

Topical decongestant 4\% Xylocaine with 1:100.000 adrenaline solution using applicators like cottonoid strips.

\section{PROCEDURES}

\section{Endoscopy was Performed by Three Passes}

1. Pass: Along the floor of nasal cavity towards nasopharynx to visualize the status of inferior turbinate and meatus, Eustachian tube orifice, nasopharyngeal mucosa, nasolacrimal duct orifice and any pathological variations.

2. Pass: Scope was inserted along the superior surface of inferior turbinate. As the endoscope was withdrawn the sphenoid ostium, sphenoethmoidal recess, fontanelle, middle meatus, natural ostium of maxillary sinus and any pathological or anatomical variations were noted.

3. Pass: Is to visualize the frontal recess. A gentle medial subluxation of middle turbinate or use of a cannula placed under middle turbinate helps the introduction of the scope in middle meatus.

These patients after detailed evaluation and routine investigations were submitted for CT scan paranasal sinuses prior to functional endoscopic sinus surgery. As per the protocol chronic sinusitis was defined as nasal blockade, anterior nasal discharge, postnasal drip, headache or facial pain, abnormalities of smell. These patients were refractory to medical treatment for more than 3 months' duration. All CT scans were obtained with Siemens Somatom AR star, spiral scanner (Forchheim, Germany).

After obtaining the scout projection, the area of scanning was defined to include the region from roof of frontal sinus up to the hard palate. Axial sections were performed with the patient in supine position and the plane of data acquisition parallel to hard palate. The sections were taken with slice thickness of $5 \mathrm{~mm}$ and table feed of $7 \mathrm{~mm}$, i.e. pitch of 1.4 . Images were reconstructed at $4 \mathrm{~mm}$ intervals, i.e. image overlap of $1 \mathrm{~mm}$. Scanning parameters included $105 \mathrm{~mA}, 130$ $\mathrm{kV}$ and tube rotation time of 1.5 seconds.
Coronal sections were performed with the patients in prone position with extended neck and the plane perpendicular to axial plane. The scan parameters were same as in axial plane. Extended cephalic/caudal sections were done in a few patients to see extension of the disease process.

\section{OBSERVATION AND RESULTS \\ Variations}

\section{Skull Base Types}

The following was the incidence of various skull base types.

1. Keros Type I: $6(12 \%)$.

2. Keros Type II: 32 (64\%).

3. Keros Type III: 12 (24\%).

\begin{tabular}{|c|c|c|}
\hline \multicolumn{3}{|c|}{ SKULL BASE TYPES } \\
\hline Variation & Number & Percentage \\
\hline Keros Type I & 6 & 12 \\
\hline Keros Type II & 32 & 64 \\
\hline Keros Type III & 12 & 24 \\
\hline Table 1: Showing Variations of Skull Base Configuration \\
\hline
\end{tabular}

\section{Agger Nasi}

Pneumatization of agger nasi was seen in 58 (72.5\%) nasal cavities. When present, the agger cells were always bilateral.

\section{Frontal Sinus}

The frontal sinus was present in 95 (93.5\%) sides, absent in 5 (6.25\%) sides and Hyperpneumatized in 14 (27.5\%). The sinus was larger on the right in 24 subjects and on the left in 26 subjects. Interfrontal cells were seen in $8(16 \%)$.

\section{Frontal Recess}

The frontal recess was found to be obstructed in 14 of 75 $(18 \%)$. Of these $8(57 \%)$ were on the right and $6(43 \%)$ were on the left. The obstruction was caused by agger nasi cells in 6 (43\%), ethmoidal bulla or accessory cells in 4 (28.5\%) and polyps in $4(28.5 \%)$

\section{Middle Turbinate}

\begin{tabular}{|c|c|c|}
\hline Variation & Number & Percentage \\
\hline Typical & 25 & 50 \\
\hline Paradoxically curved & 6 & 12 \\
\hline Pneumatized & 17 & 34 \\
\hline Large non-pneumatized & 2 & 4 \\
\hline \multicolumn{2}{|c|}{ Table 2: Middle Turbinate Variations } \\
\hline
\end{tabular}

\section{Uncinate Process}

The uncinate was typical in 29 (58\%), medialized in 22 (44\%), anteriorly turned in $1(2 \%)$, hypertrophied in $6(12 \%)$ and pneumatized in $2(4 \%)$.

The superior attachment of the uncinate process was as follows: middle turbinate in 21 (42\%), lamina papyracea in 18 (36\%) and skull base in 11 (22\%).

\begin{tabular}{|c|c|c|}
\hline Attachment & Number & Percentage \\
\hline Middle turbinate & 21 & 42 \\
\hline Lamina papyracea & 18 & 36 \\
\hline Skull base & 11 & 22 \\
\hline
\end{tabular}

\section{Ethmoidal Bulla}

The bulla was typical in 31 (62\%), large in 11 (22\%) and hypoplastic in $8(16 \%)$. 


\begin{tabular}{|c|c|c|}
\hline Typical & 31 & 62 \\
\hline Large & 11 & 22 \\
\hline Hypoplastic & 8 & 16 \\
\hline \multicolumn{2}{|c|}{ Table 4: Ethmoidal Bulla Variations } \\
\hline
\end{tabular}

\section{Supraorbital Cells}

Supraorbital ethmoid pneumatization was seen in 18 (36\%). Of these $10(20 \%)$ were on the right and $8(16 \%)$ were on the left. In $8(16 \%)$ patients, it was bilateral.

\section{Maxillary Intrasinus Septa}

An intrasinus maxillary septum can convert the maxillary sinus into two chambers. In our study, we found maxillary sinus septation in 5\%. All the intrasinus septae were running obliquely along the longest diameter. This finding is important; in that a part of the maxillary sinus can have impaired drainage, while the rest of it is normal.

\section{Accessory Ostia}

Accessory maxillary sinus ostia were seen in 12 (24\%). Of these, $8(16 \%)$ nasal cavities showed accessory ostia in anterior fontanelle and $4(8 \%)$ in the posterior fontanelle.
In $2(4 \%)$ of patients, there were multiple accessory ostia.

\section{Haller Cell}

Haller cell was seen in $3(6 \%)$.

\section{Sphenoid Sinus}

The various patterns of pneumatization seen were: absent in 1 (2\%), conchal in $1(2 \%)$, presellar in $12(24 \%)$ and sellar in 36 $(72 \%)$.

The Various Intrasphenoidal Projections Seen Were

1. Optic nerve in 19 (38\%).

2. Maxillary nerve in $14(28 \%)$.

3. Vidian nerve in 17 (34\%).

4. Unable to see internal carotid artery projections due to most of the CT PNS taken by coronal cuts in our centre.

\section{Onodi Cell}

Onodi cells were seen in $18(36 \%)$. Of these $10(20 \%)$ were on the right and $8(16 \%)$ were on the left. In 7 (14\%) of patients, it was bilateral.

\begin{tabular}{|c|c|c|c|c|c|c|}
\hline $\begin{array}{c}\text { Sl. } \\
\text { No. }\end{array}$ & $\mathbf{1}$ & $\mathbf{2}$ & $\mathbf{3}$ & $\mathbf{4}$ & $\mathbf{5}$ & $\mathbf{6}$ \\
\hline Parameter & $\begin{array}{c}\text { Middle } \\
\text { Turbinate }\end{array}$ & Middle Meatus & $\begin{array}{c}\text { Bulla } \\
\text { Ethmoidalis }\end{array}$ & $\begin{array}{c}\text { Hiatus } \\
\text { Semilunaris }\end{array}$ & Frontal Recess & $\begin{array}{c}\text { Sphenoethmoid } \\
\text { Recess }\end{array}$ \\
\hline Normal DE(N)+CT (N) & 38 & 27 & 32 & 25 & 51 & 32 \\
\hline Abnormal DE(A)+CT(A) & 35 & 46 & 13 & 30 & 27 & 3 \\
\hline False positive DE(A)+CT(N) & 12 & 8 & 8 & 2 & 3 & 0 \\
\hline False negative DE(N)+CT(A) & 7 & 13 & 10 & 22 & 5 & 8 \\
\hline Sensitivity & 74.47 & 85.19 & 61.9 & 93.75 & 90 & 100 \\
\hline Specificity & 84.44 & 67.50 & 76.19 & 53.19 & 91.07 & 80 \\
\hline Predictive +ve & 83.33 & 77.97 & 56.52 & 57.69 & 84.38 & 27.27 \\
\hline Predictive -ve & 76.00 & 77.14 & 80 & 92.59 & 94.44 & 100 \\
\hline
\end{tabular}

The parameters correlated in our study include middle turbinate, middle meatus, bulla ethmoidalis, hiatus semilunaris, frontal recess and sphenoethmoid recess. The false positive, false negative, sensitivity and specificity (Table 5) were calculated for diagnostic endoscopy as compared to CT findings. Diagnostic endoscopy was found to have sensitivities for frontal recess, hiatus semilunaris and sphenoethmoidal recess as $90 \%, 94 \%$ and $100 \%$ respectively. While sensitivity for middle turbinate, bulla ethmoidalis and middle meatus was $74 \%, 62 \%$ and $85 \%$ respectively.

The sensitivity of diagnostic endoscopy for frontal recess, middle turbinate and bulla ethmoidalis was found as $91 \%, 84 \%$ and $76 \%$ respectively and for sphenoethmoidal recess hiatus semilunaris and middle turbinate as $80 \%, 53 \%$ and $67 \%$ respectively. So diagnostic endoscopy was found to be more sensitive for frontal recess, sphenoethmoidal recess and hiatus semilunaris and more specific for middle turbinate, bulla ethmoidalis.

\section{DISCUSSION}

\section{Agger Nasi Cells}

We found pneumatization of the agger nasi cells in $72.5 \%$. In all patients, the pneumatization when present was bilateral. The prevalence of agger nasi cells varies widely as reported by various workers: 10-15\% (Messerklinger.3); 14\% (Lloyd et al. ${ }^{4}$ ); 65\% (Davis.5); 89\% (Van Alyea. ${ }^{6}$ ) and 100\% (Kennedy and Zinreich.7). Depending on the degree of pneumatization. Agger nasi cells may reach laterally to the lacrimal fossa and superiorly to cause narrowing of frontal recess.

On coronal CT, these cells appear inferior to frontal recess and lateral to the middle turbinate. Because of this intimate relationship, these cells form excellent surgical landmarks. Opening the agger nasi cells usually provides a good view of the frontal recess. Therefore, identification of this variation is important in diagnosis and treatment of recurrent or chronic frontal sinusitis.

\section{Frontal Sinus}

We found the prevalence of non-pneumatization of frontal sinus in $6.25 \%$. This correlates with the study by Natsis K. ${ }^{8}$ who reported a prevalence of $5 \%$.

In all our patients, frontal sinuses on either sides were always asymmetrical with right being large in $47.5 \%$ and the left sinus being large in $52.5 \%$.

\section{Frontal Recess}

As the axis of the frontal recess is tilted approximately 50 degrees to the canthomeatal line, this drainage pathway cannot be included entirely within a single coronal section. Therefore, coronal oblique views are required for complete information. 
In our study, we found that the frontal recess was obstructed in $18 \%$. Of these, in $43 \%$ the obstruction was by agger nasi cells, in $28.5 \%$ by ethmoid bulla or accessory cells and in $28.5 \%$ by polyps. As the natural ostium of the frontal sinus is very wide with average anteroposterior diameter of $7.22 \mathrm{~mm}$ and transverse diameter of $8.92 \mathrm{~mm}$, the obstruction to the frontal sinus drainage and ventilation most often lies in the frontal recess rather than the ostium as is evident from our results. Therefore, merely clearing the recess is sufficient to achieve patency of frontal sinus ostium in most cases.

\section{Middle Turbinate}

Typically, the middle turbinate is said to have convex medial and concave lateral surfaces with smooth uniform curvature with no obstruction to middle meatus and adequate space between the turbinate and septum. However, the middle turbinate is known for several variations.

\section{Pneumatized Middle Turbinate}

We found pneumatized middle turbinate in $50 \%$. Of these, $44 \%$ showed lamellar pattern, $4 \%$ showed bulbous pattern and $52 \%$ showed true concha bullosa. The origin of the pneumatization can sometimes be seen as depressions on the lateral surface. Literature reports a wide variation in the incidence of middle turbinate pneumatization and is as follows: Joe JK. ${ }^{9}$ et al.-15\%; Liu X. ${ }^{10}$ et al.-34.85\%, Basic N. ${ }^{11}$ et al.-42\%, Lothrop. ${ }^{12-9 \%}$, Davis -8\%, Shaeffer.13-11\%.

Our results are close to that reported by Liu X et al.10 Presence of a concha bullosa does not suggest a pathological finding. However, in the setting of chronic sinus disease, resection of the concha bullosa should be considered to improve paranasal sinus access. Further, the concha bullosa interior may be affected by disease in other sinuses.

\section{Bulla Ethmoidalis}

We defined a hypoplastic bulla as one in which the distance between the lateral surface of middle turbinate and summit of bulla was more than 4 to 5 millimetres. An enlarged bulla ethmoidalis was defined as one that contacts or extends beyond the free margin of the uncinate and middle turbinate. This can result in a narrow hiatus semilunaris. We found large ethmoidal bulla in $22 \%$. This correlates with the reported frequency by Lloyd. ${ }^{14}$ (17\%) and Lund VJ. ${ }^{15}$ (18\%).

\section{UNCINATE PROCESS}

\section{The Superior Attachment}

The superior attachment of uncinate process is important for the following reasons. When the uncinate process is attached to the skull base or middle turbinate, the frontal recess opens into the ethmoidal infundibulum and can be involved in infundibular disease. When the superior attachment is to the lamina papyracea, the frontal sinus opens into the middle meatus directly and can be spared from infundibular disease. Further, during surgery this attachment needs to be cleared before gaining access to frontal recess. In our study, we found that the superior attachment was to middle turbinate in $42 \%$, lamina papyracea in $36 \%$ and skull base in $22 \%$.

\section{Deviated Uncinate Process}

In our study, we found medially turned uncinate process in $44 \%$ and anteriorly turned uncinate process in $2 \%$. This correlates well with $45.27 \%$ deviations reported by Liu X et al. and 31\% deflection reported by Danese M.
Normally, the uncinate is a sagittally-oriented structure with adequate space between it and bulla ethmoidalis, middle turbinate and lamina papyracea. The medial deflection may contact the middle turbinate or can narrow the middle meatus. A lateral deflection of the uncinate process will make the infundibulum narrow. Because of the reduced distance between the lateralized uncinate process and lamina papyracea, care needs to be taken while performing uncinectomy to prevent orbital injury. An anteriorly bent uncinate process gives the impression of double middle turbinate on endoscopy.

\section{Pneumatized Uncinate Process}

We found this variation in $4 \%$. This correlates with the prevalence reported by Kennedy ( 0 to $4 \%$ ) and Bolger et al. $(2.5 \%)$. The pneumatized uncinate is called uncinate bulla and can narrow the infundibulum, frontal recess and middle meatus.

\section{Maxillary Intrasinus Septa}

An intrasinus maxillary septum can convert the maxillary sinus into two chambers. According to Prahlada NB. This is present in $1 \%$ to $6 \%$ of the population. Earwaker reported a prevalence of $2.38 \%$ in his study. In our study we found maxillary sinus septation in $5 \%$, which is consistent with that reported by Prahlada NB. All the intrasinus septae were running obliquely along the longest diameter. This finding is important, in that a part of the maxillary sinus can have impaired drainage while the rest of it is normal.

\section{Accessory 0stia}

The accessory ostia of the maxillary sinus are present in the anterior and posterior nasal fontanelles, the bone deficient areas in lateral nasal wall behind and below uncinate process. In our study, accessory ostia were present in $15 \%$ of nasal cavities. Earwaker has reported an incidence of $13.75 \%$. Our results are very close to that of Earwaker.

\section{Onodi Cell}

This is a posterolateral pneumatization of posterior ethmoidal cell coming into intimate relationship with optic nerve. On coronal CT, an Onodi cell is seen above the sphenoid sinus. Endoscopically, these cells appear as outgrowths of posterior ethmoids posteriorly and superiorly. They have a pyramidal configuration with the tip of the pyramid pointing away from the endoscopist. It is said to have a higher incidence in Asians. In our study, the prevalence of Onodi cells was $22.5 \%$. The prevalence of Onodi cells according to various workers are: Earwaker. ${ }^{16}-24 \%$, Aibara. ${ }^{17}-7 \%$, Basic. $-10 \%$. Our results are comparable to that of Earwaker.

\section{Haller Cells}

Also called infraorbital ethmoidal cells, these are anterior ethmoidal cells pneumatizing the floor of the orbit or the roof of the maxillary sinus. In view of their location precisely above the region of the maxillary sinus ostium and infundibulum, they can cause narrowing of maxillary sinus ostium or infundibulum, thus predisposing to recurrent maxillary sinusitis. In our study, Haller cells were present in 3.75\%. The frequency with which these cells are encountered varies in literature from $1 \%$ to $45.1 \%$ and is as follows. Liu X. $-1 \%$; Jones. ${ }^{18}-6 \%$; Shroff. ${ }^{19}-6 \%$; Zinreich. $-10 \%$; Lloyd. -15\%; Yadav. $^{20}-28 \%$; Stackpole and Edelstein. ${ }^{21}-34 \%$; Bolger. ${ }^{22}$ $45.1 \%$. 
The wide discrepancy noted in literature in the prevalence of these cells may be related to the differences in the interpretation of these cells.

\section{Ethmoidal Labyrinth Cells which Outwardly Excavate the Os Planum and Os Maxillae}

Cell inferior to the ethmoid bulla adhering to the roof of the maxillary sinus, in continuity with the proximal infundibulum which formed part of the lateral wall of the infundibulum: Zinreich and Kennedy. In addition to the above description, cells precisely in the region of the maxillary sinus.

\section{Ostium: Stammberger}

A large cell representing a point of access between the inferior part of the ethmoid base and the posterosuperior part of the nasal surface of the maxilla behind and above the hiatus semilunaris: Kimpoti, Nemanic, et al.

Ethmoid bulla occupying a lower position than normal whereby the outer wall of the lowest cell is formed by the orbital wall of the superior maxilla instead of the lamina papyracea: Skillern. Air cells located below the ethmoid bulla, along the maxillary sinus roof and most inferior portion of lamina papyracea including air cells located within the infundibulum.

\section{Bolger et al.}

\section{Supraorbital Ethmoidal Cells}

The ethmoid air cells can extend supraorbitally and is said to be present in $15 \%$ to $21 \%$ according to Bhatt NJ. In our study we found a prevalence of $22.5 \%$ which corresponds to that reported by Bhatt NJ.

\section{Intrasphenoidal Projections}

Due to extensive pneumatization, certain vital structure that are normally in the neighbourhood of sphenoid, actually project inwards. We found the following prevalence of intrasphenoid projections: Optic nerve in 38\%, maxillary nerve in $28 \%$ and vidian nerve in $34 \%$. The true prevalence of internal carotid artery projections or dehiscence could not be ascertained as axial CT sections were not obtained in our patients. The prevalence of intrasphenoid projections according to Van Alyea is optic nerve in $40 \%$, maxillary nerve in $40 \%$ and vidian nerve in $36 \%$. According to Lang. they are as follows: Optic nerve in 19\%, maxillary nerve in $28.6 \%$, vidian nerve in $14.3 \%$.

\section{Sphenoid Sinus Pneumatization}

The pneumatization of the sphenoid sinus can vary from total non-pneumatization to hyperpneumatization including clinoid processes, sphenoid wings and pterygoid plates. In our study, we found absent pneumatization $2.5 \%$, conchal type in $2.5 \%$, presellar type in $22.5 \%$ and sellar in $72.5 \%$. These findings compare well with that reported by Lang. ${ }^{23}$ (Conchal $0 \%$, presellar $23.8 \%$, sellar $76.2 \%$ ) and by Congdon (Conchal $5 \%$, presellar $28 \%$, sellar $67 \%$ ).

\section{Skull Base Configuration}

The roof of the ethmoid bone is formed by the fovea ethmoidalis laterally and the cribriform plate medially. The lateral lamella of the cribriform plate is thin and may be of substantial height making it vulnerable to injury. The anatomy of the anterior ethmoid is critical for two reasons. First, this area is most vulnerable to iatrogenic cerebrospinal fluid leaks. Second, the anterior ethmoid artery is vulnerable to injury which can cause devastating bleeding into the orbit. In our study, we found Keros type I (1 to $3 \mathrm{~mm}$ deep) olfactory fossa in $12 \%$, type II ( 4 to $7 \mathrm{~mm}$ ) in $64 \%$ and type III ( 8 to 16 $\mathrm{mm}$ ) in $24 \%$. Though several authors draw attention to the importance of deep skull base conformation, we did not find any studies reporting the incidence of various types of conformations. Arslan et al. ${ }^{24}$ reported that average depth was $8 \mathrm{~mm}$ on right side and $9.5 \mathrm{~mm}$ on the left side.

\section{CONCLUSION}

All the variations of sinonasal anatomy described in literature except the presence of supreme turbinate were encountered in our study. The medialized uncinate process (Double middle turbinate) was most common uncinate process variation and pneumatized middle turbinate was the most common middle turbinate variation. Extramural pneumatization like septal, supraorbital, sphenoid wing and pterygoid plates was quite common. The depth of olfactory fossa was of Keros type II in majority of patients.

In view of the presence of these significant variations, we reemphasize the need for proper preoperative assessment in every patient in order to accomplish a safe and effective endoscopic sinus surgery.

\section{REFERENCES}

1. Ian S Mackay, Bull TR. Scott Brown's otolaryngology. Rhinology. Butterworth-Heinemann; 1997;Vol 4.

2. Stammberger $\mathrm{H}$, Wolfgang K. Functional endoscopic sinus surgery-the messerklinger technique. Decker BC; 1991.

3. Messerklinger $\mathrm{W}$. Uber die drainage der menschlichen nasennebenhohlen unter normalen und pathologischen bedingungen. Mitteilung. Mschr. Ohrenheilk 1966;100:5668.

4. Lloyd GAS, Lund VJ, Scadding GK. Computerised tomography in the preoperative evaluation of functional endoscopic sinus surgery. J of Laryngol and Otol 1991;105:181-185.

5. Davis WE. Anatomy of the paranasal sinuses. OCNA 1996;29:57-73.

6. Van Alyea. Ethmoid labyrinth: anatomic study with consideration of clinical significance of its structural characteristics. Arch Otolaryngol 1939;29(6):881-902.

7. Zinreich SJ, Kennedy DW, Gayler BW. CT of nasal cavity, paranasal sinuses: an evaluation of anatomy in endoscopic sinus surgery. Clear Images 1988;2:2-10.

8. Natsis K, Karabatakis V, Tsikaras P, et al. Frontal sinsus anatomical variations with potential consequences for the orbit. Study on cadavers. Morphologie 2004;88(280):35-8.

9. Joe JK, Ho SY, Yanagisawa E. Documentation of variations in sinonasal anatomy by intra-operative nasal endoscopy. Laryngoscope 2000;110(2 Pt 1):229-35.

10. Liu $\mathrm{X}$, Zhang $\mathrm{G}, \mathrm{Xu}$ G. Anatomic variations of the ostiomeatal complex and their correlation with chronic sinusitis: CT evaluation. Zhonghua Er Bi Yan Hou Ke Za Zhi 1999;34(3):143-6.

11. Basic N, Basic V, Jukic T, et al. Computed tomographic imaging to determine the frequency of anatomical variations in pneumatization of the ethmoid bone. Eur Arch Otorhinolaryngol 1999;256(2):69-71. 
12. Lothrop HA. The anatomy of the inferior ethmoidal turbinate bone with particular reference to cell formation. Surgical importance of such ethmoid cell. Ann Surgery 1903;38:233-255.

13. Shaeffer SD. An anatomic approach to endoscopic intranasal ethmoidectomy. Laryngoscope 1998;108(11 Pt 1):1628-34.

14. Lloyd GA, Lund VJ, Scadding GK. CT of the paranasal sinuses and functional endoscopic surgery: a critical analysis of 100 symptomatic patients. J Laryngol Otol 1991;105(3):181-5.

15. Lund VJ, Holmstrom M, Scadding GK. Functional endoscopic sinus surgery in the management of chronic rhinosinusitis. An objective assessment. J Laryngol Otol 1991;105(10):832-5.

16. Earwaker J. Anatomic variants in sinonasal CT. Radiographics 1993;13(2):381-415.

17. Aibara R, Kawakita S, Yumoto E, et al. Relationship of onodi cell to optic neuritis-radiological anatomy on coronal CT scanning. Nippon Jibiinkoka Gakkai Kaiho 1997;100(6):663-70.
18. Jones NS, Strobl A, Holland I. A study of the CT findings in 100 patients with rhinosinusitis and 100 controls. Clin Otolaryngol Allied Sci 1997;22(1):47-51.

19. Shroffmm, Shetty PG, Kirtane MV. Coronal screening sinus CT in inflammatory sino-nasal disease. Indian J of Radiol and Imaging 1996;6:3-17.

20. Yadav SPS, Asruddin, Yadav RK, et al. Low dose CT in chronic sinusitis. Indian Journal of Otolaryngology 1999;52(1):17-22.

21. Stackpole SA, Edelstein DR. The anatomic relevance of the haller cell in sinusitis. Am J Rhinol 1997;11(3):219-23.

22. Bolger WE, Butzin CA, Parsons DS. Paranasal sinus bony anatomic variations and mucosal abnormalities: CT analysis for endoscopic sinus surgery. Laryngoscope 1991;101(1 Pt 1):56-64.

23. Lang J. Clinical anatomy of the nose, nasal cavity and paranasal sinuses. Thieme medical publishers. New York; 1989.

24. Arslan H, Aydinlioglu A, Bozkurt M, et al. Anatomic variations of the paranasal sinuses: CT examination for endoscopic sinus surgery. Auris Nasus Larynx 1999;26(1):39-48. 